\title{
Intermediate Effect Biomarkers--Alternatives to Direct Concentration- Response Data for Regulatory Benefits Analyses
}

\author{
Dale Hattis ${ }^{*}$
}

George Perkins Marsh Institute, Clark University, 950 Main Street, Worcester, MA 02476, USA

\begin{abstract}
Perceived needs for extensive chemical-specific toxicological information have impeded efforts to assess risks and evaluate likely public health protection benefits of possible standards for hazardous air pollutants (HAPs). This paper discusses opportunities to use effects of HAPs on early effect biomarkers, such as birth weights, to predict likely changes in rare quantal effects of concern that would be relevant for the quantification of likely regulatory benefits from exposure reductions. In the birth weight example, even modest exposures to common air pollutants can be seen as producing a kind of tax on the limited resources available to the fetus to grow and develop. In contrast to teratogenic effects, dose response relationships for fetal growth restriction in animals are often nearly linear, suggesting that the developing fetus may not generally have untapped "functional reserve capacity" that is expected to buffer the effects of modest exposures to toxicants in the traditional toxicological paradigm. Given this mechanistic perspective, supported in part by parallel dose response relationships between reported cigarette smoking and both birth weight and infant mortality, restriction on fetal growth can be associated with changes in quantal end effects of concern that are more difficult to assess directly in epidemiological studies.
\end{abstract}

Keywords: Fetal growth restriction, infant mortality, early effect biomarkers.

\section{INTRODUCTION}

Perceived needs for extensive chemical-specific toxicological information have impeded efforts to assess risks and evaluate likely public health protection benefits of possible standards for hazardous air pollutants (HAPs). This paper describes the second of two proposed approaches that regulatory toxicologists may use to analyze risks and associated uncertainties for noncancer effects of HAPs with limited toxicological databases. Both approaches show new ways to leverage human experimental and epidemiological data to draw inferences about human risks.

The first approach (described in the conference proceedings [1], and expected to be published elsewhere) treats HAPs as random draws from reference sets of putatively analogous chemicals that have been studied in the past. The variability among previously studied chemicals is used to create distributions that represent each of the concerns that are addressed by traditional "uncertainty factors" in the derivation of reference concentrations (RfCs) $[2,3]$. This approach builds on previous work by adding the ability incorporate the expected implications for risks of a user-specified incidence of effects from interacting background processes, as recommended in a recent report by the National Research Council [4] (2008).

This paper describes another approach toward risk assessments for HAPs, based on a growing set of human biomarkers of early effect that allow assessors to "move upstream" from ultimate endpoints of concern [5]. Using

\footnotetext{
*Address correspondence to this author at the George Perkins Marsh Institute, Clark University, 950 Main Street, Worcester, MA 02476, USA; Tel: 508-751-4603; Fax: 508-751-4600;

E-mails: Dhattis@clark.edu,dhattis@aol.com
}

these biomarkers, projections of potential health risks are made in two steps: (1) assess relationships between exposure to the chemical of interest and the intermediate biomarker of effect using limited chemical-specific information, and (2) if the biomarker can be assumed to be a reasonable proxy for causal processes leading to the apical endpoint, use preestablished relationships between the biomarker and risks of apical adverse effects to assess the changes in the apical effects that are likely to be associated with changes in exposure to the air pollutant (Fig. 1).

\section{OVERVIEW OF THE TWO-STAGE APPROACH USING EARLY BIOMARKERS OF EFFECT}

Generally, the biomarkers that are potentially useful for this two-step approach are continuous parameters (e.g., birth weight, sperm counts, lung-function measurements) where each measurement inherently can convey a considerable amount of information. On the other hand, the effects of ultimate concern that are easier for economists to work with in valuation studies are often quantal (dichotomous classification, e.g. dead $v s$ alive, with or without a particular tumor or other condition) parameters for which changes are more difficult to measure directly in relation to toxicant exposures in epidemiological studies.

Several candidate biomarkers are available for this approach, including

- Fetal growth restriction indicated by birth weight differences as predictors of infant mortality [6,7] and other adverse effects later in life $[8,9]$.

- Semen quality differences as predictors of male fertility differences [10-12].

- Differences in traditional cardiovascular risk factors (e.g., blood pressure, serum cholesterol) and some 


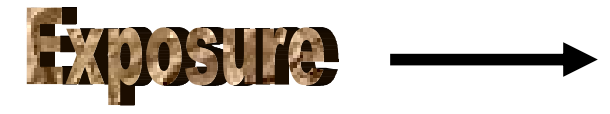

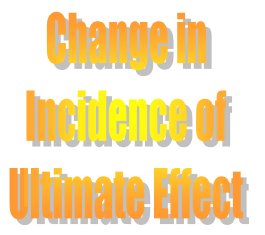

\section{(Rare Quantal Effect, Important but Statistically Noisy; Hard to Measure)}

Fig. (1). General Schema for the Use of Intermediate Biomarkers of Effect to Quantify Apical Effects of Ultimate Concern.

newer risk factors (heart rate variability, serum fibrinogen, and some lung functions) as predictors of cardiovascular mortality [13-18].

- $\quad$ Iodide deficiency and thyroid hormone parameters in young children as predictors of neurodevelopmental impairment [19-23]. below.

For illustration, we amplify on the first of these examples

A key observation that arises from the biomarker/health effects literature is that biomarkers typically do not need to exceed critical "thresholds" in order to have appreciable significance for predictions of public health impacts. Most often, as in the case of birth weights or blood pressures (See Fig. 2, [13]), risks change in a more or less continuous fashion in relation to biomarker levels. Thus, the health significance of biomarker changes is not usually confined to a small minority of people who are pushed from one side to another of quantitative criterion levels that physicians have defined in order to identify clinical disease states. The public health impacts generally extend through a large fraction of the population of ordinary people who would not normally be categorized as candidates for medical intervention, at least based on a single risk factor value by itself.

One of the most notable accomplishments in the past quarter century of risk assessment has been the use of physiologically based pharmacokinetic (PBPK) modeling to relate exposures to a pollutant of interest to a corresponding toxic response. Modeling likely changes in risk in this way using early-effect biomarkers continues the process of reducing a complex causal pathway to a series of discrete steps that can be separately observed and analyzed with quantitative modeling tools.

Early-effect biomarkers have another important role that they do not share with PBPK modeling. They serve to aggregate the influences of multiple stressors-both chemical and non-chemical-that act on the same biological system. Thus, birth weight can reflect effects of cigarette smoke, nutritional deficiencies, and effects from living at high altitudes, as well as any restriction of fetal growth from toxicity. Blood pressure is likely to reflect the integrated effects of salt intake, impairments of kidney function, and psychological stress from working as an air traffic controller. Motile sperm counts likely reflect both hormonal effects and the adverse effects of elevated testicular temperature from tight-fitting underwear. Thus, the use of intermediate effect biomarkers can enable risk assessors to implicitly take account of the host of interacting processes that affect health outcomes in the diverse human population, at least for a portion of the pathway to ultimate end effects.

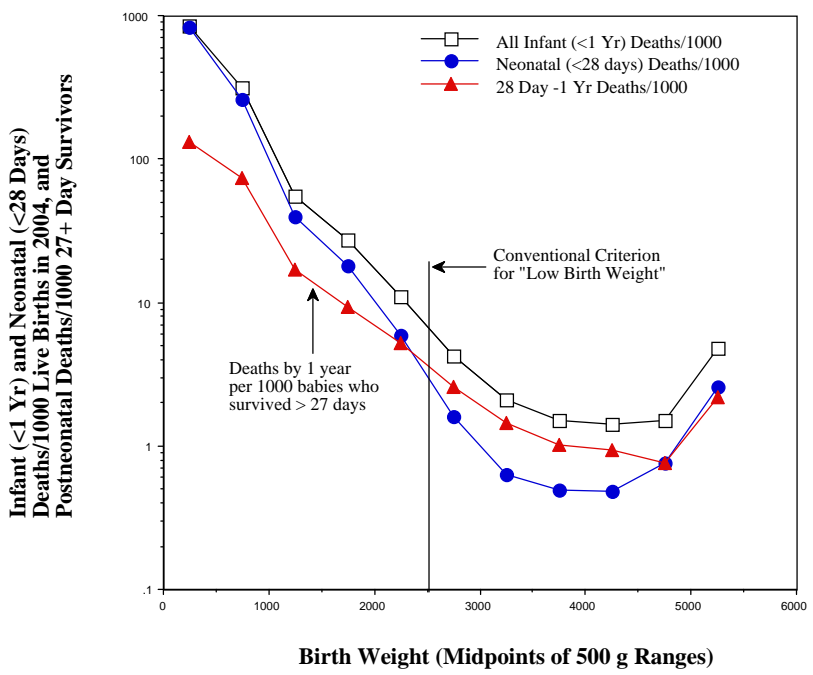

Data source: Mathews TJ. MacDorman MF. Infant mortality statistics from the 2004 period linked birth/infant death data set. National Vital Statistics Reports, 2007; 55(14) 1-32 Center for Disease Control 13 June 2007; 55(14), 1-32.

Fig. (2). Total infant mortality, neonatal and postneonatal mortality for babies of all races in the U.S. in 2004.

There is, of course, a need for caution and caveats in using this approach. The accuracy of any projection of risk with the aid of intermediate effect biomarkers depends on how well existing observations and inferred quantitative relationships for each of the two steps reflect real causal processes. For the most part, epidemiological studies yield measures of the association between variables. These associations may reflect causal processes, but may also be the result of confounding or other bias, thus causing an overestimate of the adverse effects from the exposure. On the other hand, quantitative relationships derived from epidemiological studies are notoriously subject to distortion via imperfection in the measurement of exposures (or, in the case of relationships between a biomarker and an apical response, measurements of the biomarker). There has been some use of "errors in variables" models to attempt to correct for this kind of problem [24-29] but such innovative 
analytical models are not yet common in epidemiological studies. These types of errors would tend to cause risk assessors to under predict adverse effects from exposures that affect biomarkers. Selection biases-most notably the "healthy worker effect" [30] and the "healthy worker survivor effect" [31,32] (where long-employed workers who can accumulate larger cumulative exposures to a toxicant have systematically better baseline mortality experience)can cause similar distortions. Thus, although we think the "two-step" risk assessment approach outlined here is promising, and may be a reasonable approach for initial estimates of effects, risk conclusions derived using this type of method will be subject to extensive modification with the development of improved observations and modeling tools.

Decision-making for pharmaceuticals has developed a generic solution to the problem of resolving causal versus non-causal associations: the double-blind, randomized, controlled clinical trial. Selection effects are minimized via the randomization process, and distortions from dosage measurement errors are avoided by the deliberate supply of measured amounts of test chemicals to the clinical subjects.

Such measures will seldom if ever be practically available for risk assessment and decision-making on environmental chemical exposures. However, environmental health researchers can take a few different approaches to evaluate and reduce uncertainties in the two-step quantitative inferences of risk:

- Take advantage of "experiments of nature" such as episodes of unusually large or distinctive population exposures (e.g., the air pollution episodes observed in Donora, Pennsylvania, and the infamous "London fog," which first strongly indicated effects of air pollutants on short-term mortality changes) or the temporary closing of a specific facility responsible for an important fraction of the pollutant exposures of known types in a specific area.

- Look for situations in which an exposure causes measurable changes in both the intermediate biomarker and an apical outcome of ultimate concern. Ask, "Are the changes in the incidence of the apical effect accurately predicted by the changes brought about in the early-effect biomarker by the responsible exposure?" and "Is the pattern of change in the apical effect with dose similar enough to the pattern of change in the biomarker with dose to suggest a causal relationship? For example, Fig. (3) juxtaposes the dose-response relationship between reported cigarette smoking and population-average birth weights, and the similar doseresponse relationship between reported cigarette smoking and infant mortality. Both appear to show saturation-type dose-response relationships, suggesting that the causal factor(s) for both effects may be the product of a saturable active metabolism process or a saturable receptor binding process. Quantitatively, we have found that the infant mortality effect of cigarette smoking can be understood as a combination of effects of smoking on fetal growth restriction and a shortened period of gestation (unpublished observations). More formally, an analysis of 10 million singleton live U.S. births between 1998 and 2000 [6] finds that "the effect of maternal smoking on neonatal mortality is largely mediated through reduced fetal growth.” This suggests that inferences about incremental effects on infant mortality may not be unreasonable based on the predicted or observed effects of some toxicants on fetal growth and birth weights.

- Quantitatively evaluate the experience with the predictiveness of cardiovascular risk factors for cardiovascular mortality and morbidity. Beginning in the 1950s and 1960s there were a substantial number of prospective cardiovascular disease studies that developed predictive risk relationships using multiple logistic risk equations [33]. Subsequently, the drug industry has developed a large number of pharmaceutical interventions designed to reduce the levels of specific risk factors. Generally, these interventions are likely to have been evaluated both in terms of their effects on risk factors and in terms of mortality/morbidity reductions. Risk assessors of today therefore have an opportunity to ask, for each biomarker/"risk factor," "Was the degree of mortality/ morbidity reduction achieved via the pharmaceutical intervention larger or smaller than what would have been predicted from the change in the risk factor(s) brought about by the intervention?"

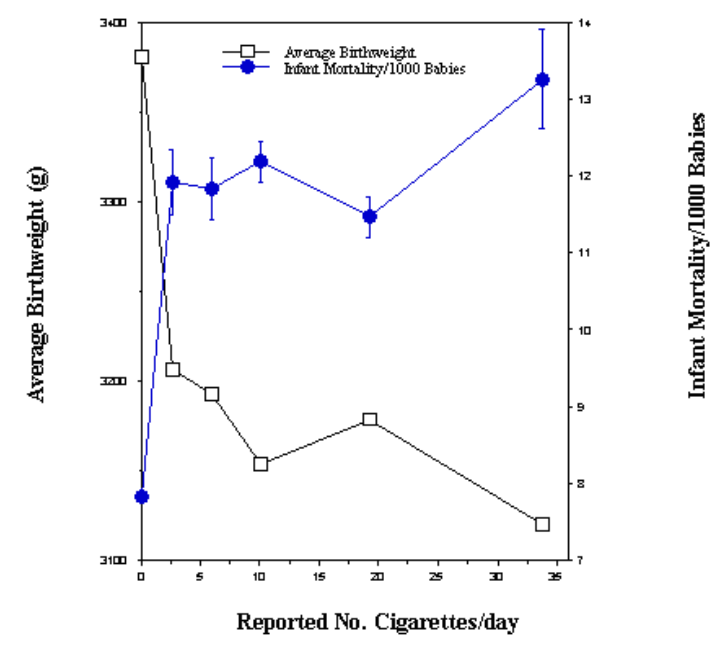

Data Source: National Center for Health Statistics. 1996. 1990 Birth Cohort Linked Birth/Infant Death Data Set, NCHS CD-ROM Series 20 No. 6, SETS Version 1.22a, issued May 1996.

Figure previously appeared in Hattis, D. "Role Of Dosimetric Scaling And Species Extrapolation In Evaluating Risks Across Life Stages. IV. Pharmacodynamic Dosimetric Considerations." Draft Report to the U.S. Environmental Protection Agency Under RFQ No. DC-030000, January 2004.

Fig. (3). Relationships between reported cigarettes smoked per day, average birth weight, and infant mortality.

\section{APPLICATION OF THE BIOMARKER APPROACH TO HAPS-THE EXAMPLE OF BIRTH WEIGHT DISTRIBUTIONS IN HUMANS}

While we do not explore here in detail the potential of all the various early-effect biomarkers that may shed light on the risks of HAPs, studies of birth weight changes in relation 
to air pollutant exposures deserve special mention and are presented as an example illustrating the application of this promising approach.

Recently, Bell et al. [34] published an epidemiological study that extends previous work from California and elsewhere on apparent relationships between exposures to various criteria air pollutants at ambient levels and birth weights in a large number of babies born in Connecticut and Massachusetts. This cohort is much larger than has been previously evaluated. Perhaps because of the large cohort size, even though exposure assessments were relatively basic (county averages), apparent effects of various pollutants were quantified with reasonably narrow confidence limits (Table 1). The findings can be brought together into a consistent framework for comparative analysis of potencies and approximate indicated population-level effects (Table 2). This type of information should be combined with other data through a thorough meta-analysis based on multiple high quality studies. Specifically, if the fetal growth restriction potency of exposures to different air toxics can be related to the potencies of these criteria pollutants through comparative animal experiments, then it seems possible to make at least approximate evaluations of population fetal growth restriction hazards of different air pollutants and comparative cost effectiveness of regulations and other policy actions (e.g., changes to the mix of fuels used in automobiles or changes in emissions from greater fuel efficiency).

In addition to infant mortality, lower birth weights are associated with some longer-term risks in adult life. A repeated finding in recent years is that relatively low birth weights in humans are strongly associated with elevated risks of Type 2 diabetes 3-7 decades after birth [35]. The data in Fig. (4) indicate that the relationship is continuous over a wide range of birth weights, and does not appear to be confined to the traditional "low birth weight" babies (under $2,500 \mathrm{~g})$.

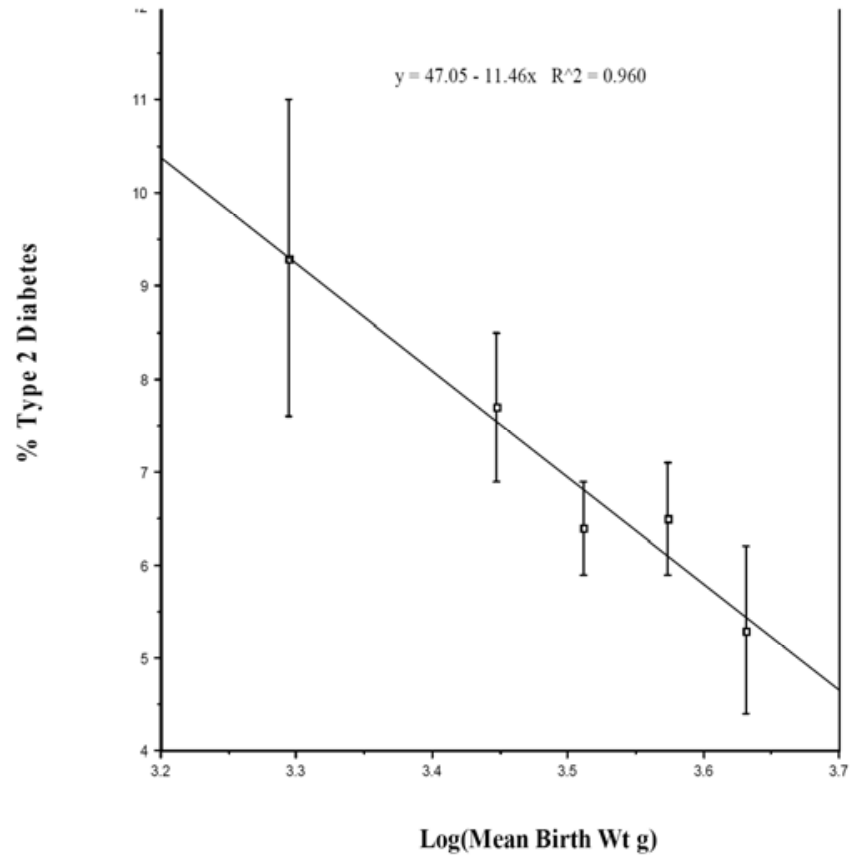

Fig. (4). Plot of the incidence of type 2 diabetes in relation to $\log$ (mean birth weight) — data of Forsen et al. (2000) [35].

Hill and Duvillié [36] review supportive mechanistic

Table 1. Basic Birth Weight Reduction Results Based on County-Average Air Pollutant Exposures During Gestation for 358,504 Babies in Massachusetts and Connecticut, Evaluated with Single-Pollutant Models, Controlling for Confounders

\begin{tabular}{|c|c|c|c|c|c|c|}
\hline $\begin{array}{c}\text { Air } \\
\text { Pollutant }\end{array}$ & $\begin{array}{c}\text { Grams Reduction Birth } \\
\text { Weight per Interquartile } \\
\text { Exposure Range }\end{array}$ & $\begin{array}{c}\text { Lower 95\% } \\
\text { Confidence Limit } \\
(\mathbf{g})\end{array}$ & $\begin{array}{c}\text { Upper 95\% } \\
\text { Confidence Limit (g) }\end{array}$ & $\begin{array}{c}\text { Mean and Std } \\
\text { Dev Exposure }\end{array}$ & $\begin{array}{c}\text { Interquartile } \\
\text { Exposure Range }\end{array}$ & $\begin{array}{c}\text { Exposure } \\
\text { Units }\end{array}$ \\
\hline \hline $\mathrm{NO}_{2}$ & 8.9 & 7 & 10.8 & $17.4 \pm 5.0$ & 4.8 \\
\hline $\mathrm{CO}$ & 16.2 & 12.6 & 19.7 & $656 \pm 180$ & 303 & $\mathrm{ppb}$ \\
\hline $\mathrm{SO}_{2}$ & 0.9 & -2.6 & 4.4 & $4.7 \pm 1.2$ & 1.6 \\
\hline $\mathrm{PM}_{10}$ & 8.2 & 5.3 & 11.1 & $22.3 \pm 5.3$ & $\mathrm{ppb}$ \\
\hline $\mathrm{PM}_{2.5}$ & 14.7 & 12.3 & 17.1 & $11.9 \pm 1.6$ & $\mu .4$ & 2.2 \\
\hline
\end{tabular}

Source: Bell et al. (2007) [34].

Table 2. Implications for Population Aggregate Birth Weight Changes of the Bell et al. (2007) Results for Pollutant Potencies (Gram Reduction in Mean Baby Weights Per Unit Exposure During Gestation) and Suggested Population Aggregate Impacts on Birth Weights

\begin{tabular}{|c|c|c|c|c|}
\hline Air Pollutant & $\begin{array}{c}\text { Indicated Potency in g Birth Weight Reduction } \\
\text { Per ppb Gas or (for Particles) } \boldsymbol{\mu g} / \mathbf{m 3}\end{array}$ & $\begin{array}{c}\text { Lower 95\% } \\
\text { Confidence Limit on } \\
\text { Potency }\end{array}$ & $\begin{array}{c}\text { Upper 95\% } \\
\text { Confidence Limit } \\
\text { on Potency }\end{array}$ & $\begin{array}{c}\text { Suggested Population } \\
\text { Aggregate Effect (g/baby) } \\
\text { (Potency } \mathbf{x} \text { Mean Exposure) }\end{array}$ \\
\hline \hline $\mathrm{NO}_{2}$ & 1.85 & 1.46 & 2.25 & 32 \\
\hline $\mathrm{CO}$ & 0.053 & 0.042 & 0.065 & 35 \\
\hline $\mathrm{SO}_{2}$ & Non-significant & & & \\
\hline $\mathrm{PM}_{10}$ & 1.1 & 0.7 & 1.5 & 25 \\
\hline $\mathrm{PM}_{2.5}$ & 6.7 & 5.6 & 7.8 & 80 \\
\hline
\end{tabular}


observations in rats-including findings that a 50 percent restriction of maternal calorie intakes from gestation day 15 through birth leads to a reduction in the mass of pancreatic beta cells-the cells that produce insulin and thereby control blood sugar levels. If dietary restriction is continued through weaning, the changes became irreversible in later life. Animals with continuing restriction through weaning are susceptible to glucose intolerance in later life. Thus, it appears that the size of the reserve capacity (pancreatic islets and beta cell numbers) built by the system for blood sugar control depends on what the system sees during developmental phases both before and after birth. A stressor (nutrient restriction in this case) can reduce the amount of reserve capacity that the system builds to provide for homeostatic control. The long-term consequence of this may be the excess incidence of Type 2 diabetes observed in people after normal aging processes have an opportunity to deplete the initially low reserve capacity to critical levels.

Similar finding have also been reported for another cardiovascular risk factor-blood pressure in human adolescents studied in the Philippines, even after correction for maternal nutrition variables [37].

The presence of mutually supportive findings in this area in both human and experimental animal systems indicates that there is good potential to use the experimental animal models to work out detailed dose-time response relationships and mechanistic pathways for the likely actions of environmental toxicants in these systems-particularly toxicants such as the disinfection byproducts, glycol ethers, and valproic acid, where there are established effects on fetal growth.

\section{MECHANISTIC PERSPECTIVES AND OBERVATIONS OF FETAL GROWTH INHIBITION IN ANIMALS}

The concept of homeostatic controls can support the plausibility of a No Adverse Effect Level (NOAEL) for a particular person (an individual threshold) for a specific mechanism of damage. However this does not necessarily imply the existence of a population threshold (a dose so low as to be at, or below, the lowest threshold dose for any individual in a mixed population with diverse sensitivities). Specifically, there may be a finite expectation for individuals to be affected by even marginal exposures in cases where even without additional exposure some people have no "functional reserve capacity" to act as a buffer between the base health state and a state of at least marginally worse health. Two specific types of cases where this can happen are:

- Some individuals in the diverse population are already suffering from various kinds of pathological dysfunction in key parameters that may be marginally affected by different toxicants (e.g., a person undergoing a myocardial infarction may have a marginally expanded area of heart muscle death if the oxygen-carrying capacity of his or her blood is reduced by a marginal exposure to additional carbon monoxide).

- $\quad$ Some individuals are presently engaged in a task (e.g., running a 100-yard dash) that taxes some physiological capabilities to their limit, and marginal exposures to a toxicant marginally reduce those physiological capabilities.

One likely example of the second type is the possibly limiting mobilization of metabolic energy to sustain growth and development during gestation. Briefly, dose-response relationships for fetal growth inhibition in relation to a variety of toxicant exposures in experimental animals, and cigarette smoking in people, suggest that marginal exposures to toxicants may impose a metabolic "tax" on the developing fetus that causes changes in developmental progress. These changes, at least on a population basis, can have potentially significant implications for public health.

One of the most common types of effects observed in reproductive/developmental studies is an inhibition of fetal growth. The current practice is to express this effect in terms of the dose causing a particular increase in the percentage of animals that have growth that is more than a standard deviation below the control mean weight. This practice implies that this effect should be treated as if it were a classical individual threshold response, to be fed into the usual NOAEL/uncertainty factor system.

However, we first noticed in a 1988 analysis of developmental effects of glycol ethers [38] that the observed pattern of dose-response relationships for fetal weight reductions differed considerably from the highly nonlinear observations of the frequency of typical teratogenic anomalies.

The impression that this category of effect often appears to be linear or nearly linear over a wide range of tested doses was strengthened by a series of observations of fetal weight responses to a variety of disinfection byproducts, prepared from data assembled by Syracuse Research for an EPAsponsored workshop in 1999 (Figs. 5-9). To reduce some of the noise in individual dose-response data sets, Fig. (10) shows the results of combining these data (with inverse variance weighting) in terms of a dosimeter labeled "Trichloroacetic Acid (TCA) equivalents" constructed from

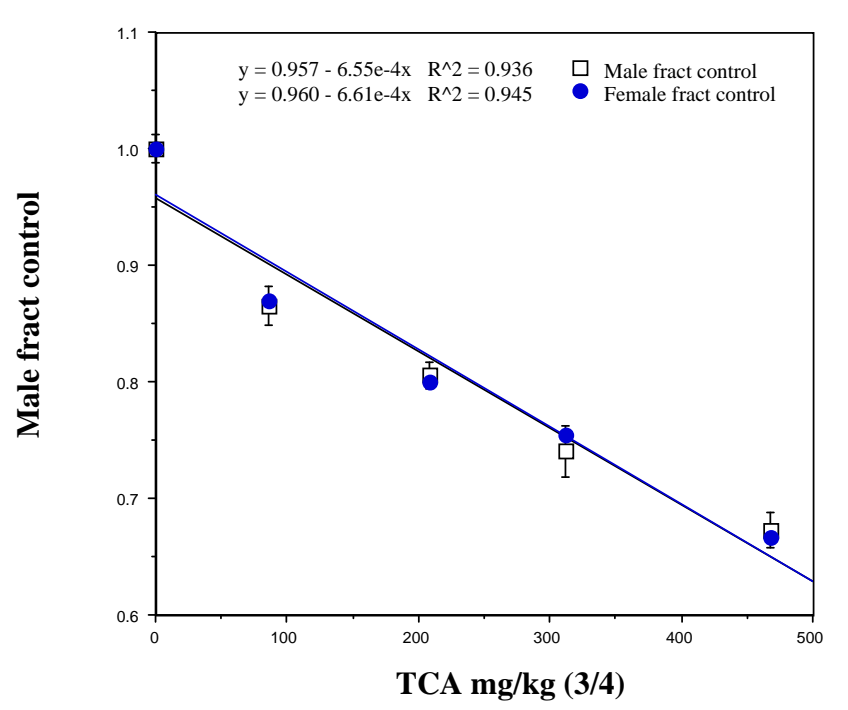

Fig. (5). Data of Smith et al. (1989) [39] on the fetal weight response of rats to trichloroacetic acid. 


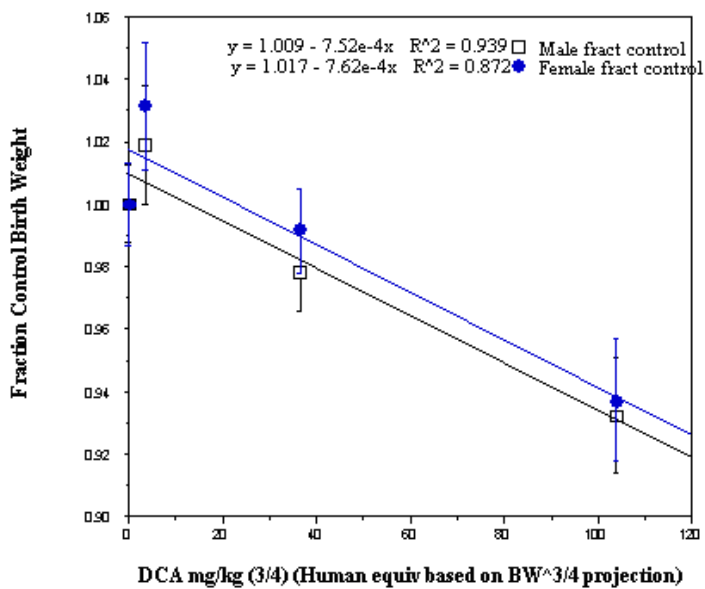

Fig. (6). Data of Smith et al. (1992) [40] on the fetal weight response of rats to dichloroacetic acid.

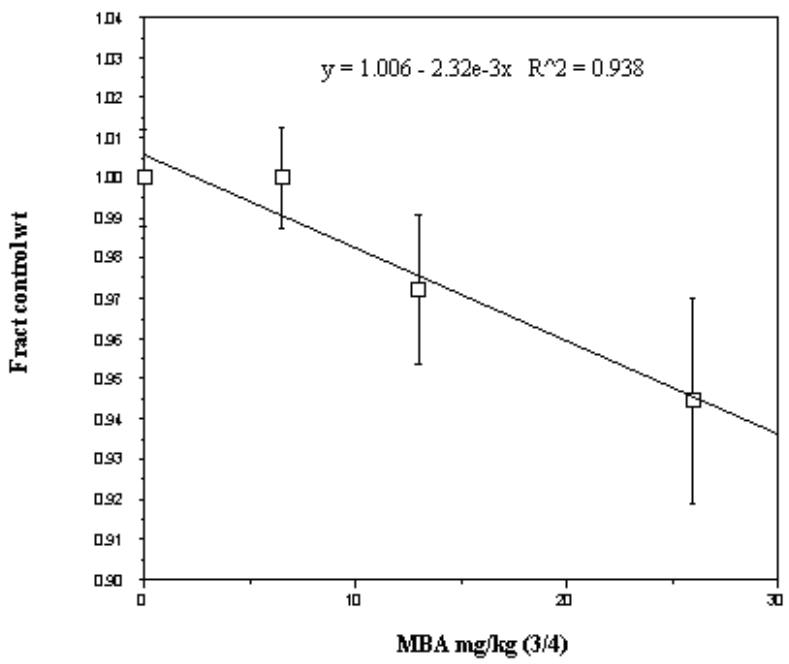

Fig. (7). Data of Randall et al. (1991) [41] on the fetal weight response of rats to monobromoacetic acid.

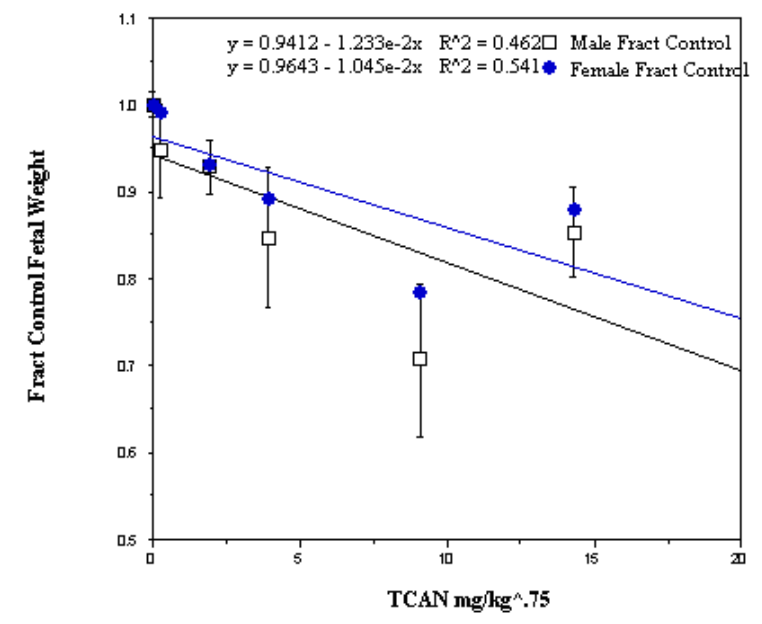

Fig. (8). Data of Smith et al. (1988) [42] on the fetal weight response of rats to trichloroacetonitrile.

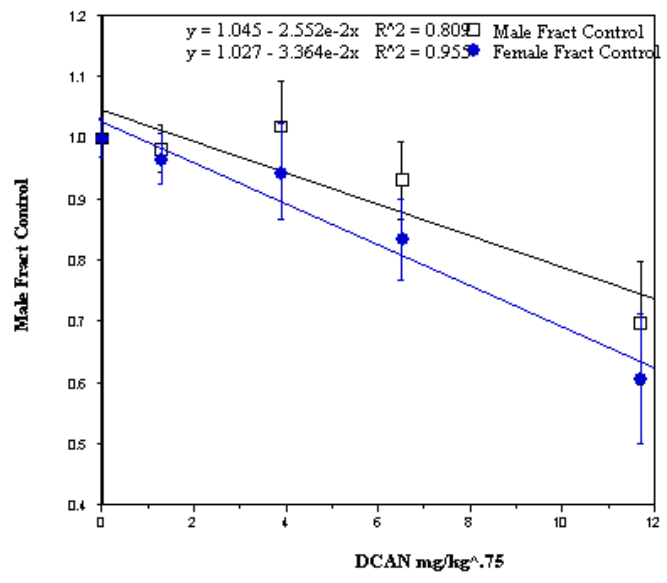

Fig. (9). Data of Smith et al. (1989) [43] on the fetal weight response of rats to dichloroacetylnitrile.

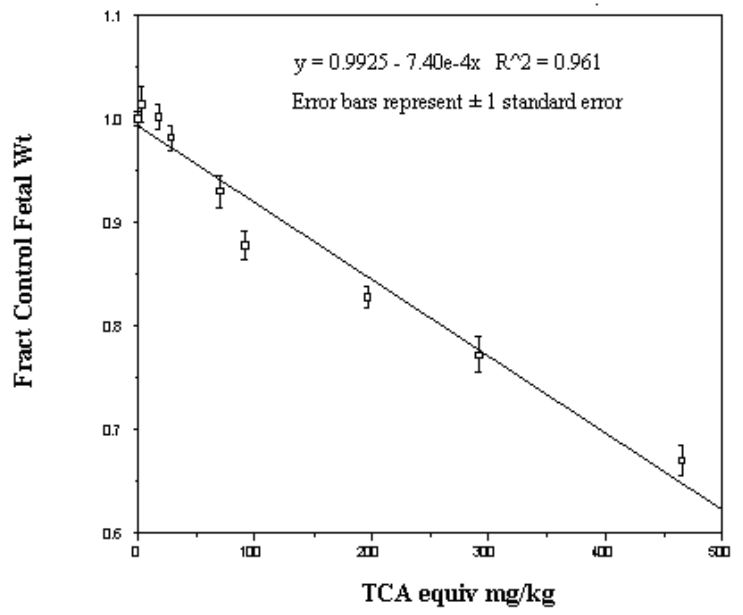

Fig. (10). Results of regression analysis of the fraction of control fetal weight response in grouped categories of TCA equivalents interpretation with a linear model.

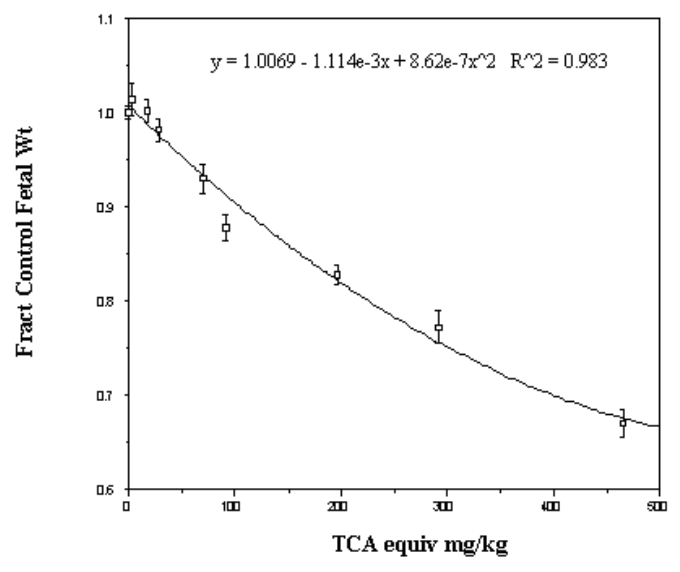

Fig. (11). Results of regression analysis of the fraction of control fetal weight response in grouped categories of TCA equivalents interpretation with a quadratic model. 


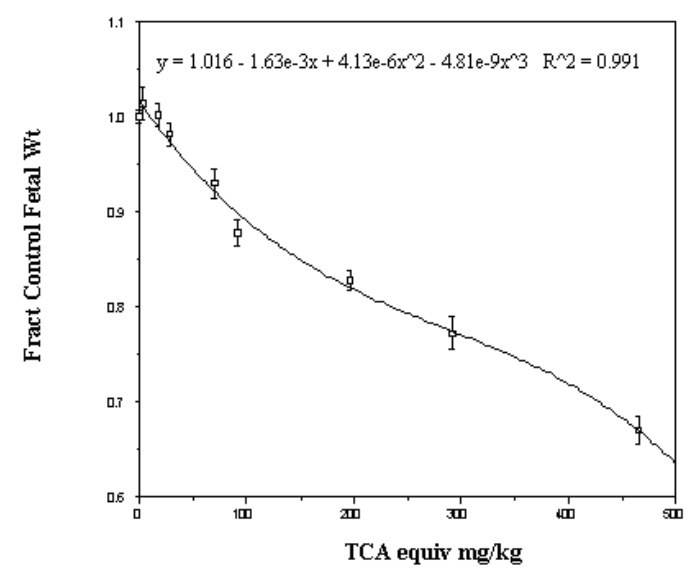

Fig. (12). Results of regression analysis of the fraction of control fetal weight response in grouped categories of TCA equivalents interpretation with a third-degree polynomial.

the slopes of the fetal weight dose-response relationships for the individual agents. Overall, the data do not appear to be incompatible with low-dose linearity, although there is some indication of smaller effects than predicted by the straight line for the lowest dose points, and also some high-dose saturation of the response. The data are also compatible with simple empirical models that incorporate quadratic and cubic terms (Figs. 11, 12).

The simplest overall interpretation of this type of finding for diverse toxicants is that the toxicants impose a kind of nonspecific "tax" on the resources that the organism would otherwise have available to grow and develop. This implies that for the case of the developing fetus, there simply may be little or no functional reserve capacity. The fetus, particularly in late pregnancy, may be mobilizing energy and other resources as fast as it can, such that even a marginal drain on these resources to counteract perturbations caused by a toxicant marginally reduces the growth and development of the organism.

In conclusion, both toxicological/mechanistic information and empirical epidemiological data can be mobilized to create insights into likely risks from environmental exposures that do not follow the traditional toxicological paradigm under which "thresholds" of zero effect at finite dose are the standard assumption.

\section{ACKNOWLEDGEMENTS}

This paper was produced as part of a presentation given at a conference (held on March 31 -April 1, 2009) on ways to do benefits analysis for regulation of air toxics by the U.S. Environmental Protection Agency, with sponsors from the EPA offices of Air and Radiation, Policy Economics and Innovation, and Research and Development. The work was done under the auspices of a contract between EPA and Abt Associates, Inc. (EP-W-05-022 WA 3-80), managed for EPA by Ron Dexter of the EPA National Center for Environmental Economics. I am grateful to Jamie Ahn for locating and assembling the data that was used to construct the plots of recent infant mortality $v s$ birth weights in Fig.
(2), and to Meghan Lynch and Abt Associates for editorial assistance.

\section{REFERENCES}

[1] Hattis D, Lynch MK. Alternatives to pollutant-by-pollutant doseresponse estimation for air toxics. White paper presented at the Workshop on Estimating the Benefits of Reducing Hazardous Air Pollutants. Washington DC: U.S. Environmental Protection Agency, 2009; Available from http://www2.clarku.edu/faculty/ dhattis/

[2] Hattis D, Lynch MK. Empirically observed distributions of pharmacokinetic and pharmacodynamic variability in humansimplications for the derivation of single point component uncertainty factors providing equivalent protection as existing RfDs. In: Lipscomb JC, Ohanian EV, Ed. Toxicokinetics in risk assessment. New York, NY: Informa Healthcare USA, Inc 2007: 69-93.

[3] Hattis D, Baird S, Goble R. A straw man proposal for a quantitative definition of the RfD. Drug Chemical Toxicol 2002; 25: 403-36.

[4] National Research Council Committee on Improving Risk Analysis Approaches Used by the U.S. EPA. Science and Decisions: Improving Risk Analysis. Washingtion, D.C.: National Academy of Sciences Press 2008.

[5] Woodruff TJ, Zeise L, Axelrad DA, et al. Moving upstream: Evaluating adverse upstream endpoints for improved risk assessment and decision-making. Environ Health Perspect 2008; 116: 1657-75.

[6] Ananth CV, Platt RW. Reexamining the effects of gestational age, fetal growth, and maternal smoking on neonatal mortality. BMC Pregnancy Childbirth [serial on the Internet] 2004; 4(1): 22./10.

[7] Pedersen CB, Sun Y, Vestergaard M, Olsen J, Basso O 2007. Assessing fetal growth impairments based on family data as a tool for identifying high-risk babies. An example with neonatal mortality. BMC Pregnancy Childbirth [serial on the Internet] 2007; 7: 28./10.

[8] Lapidus L, Andersson SW, Bengtsson C, Björkelund C, RossanderHulthén L, Lissner L.Weight and length at birth and their relationship to diabetes incidence and all-cause mortality-a 32year follow-up of the population study of women in Gothenburg, Sweden. Prim Care Diabetes 2008; 2(3): 127-33.

[9] Kajantie E, Osmond C, Barker DJ, Forsén T, Phillips DI, Eriksson JG. Size at birth as a predictor of mortality in adulthood: a followup of 350000 person-years. Int J Epidemiol 2005; 34: 655-63.

[10] Ibérico G, Vioque J, Ariza N, et al. 2004. Analysis of factors influencing pregnancy rates in homologous intrauterine insemination. Fertil Steril 2004; 81: 1308-13.

[11] Steinberger E, Rodrigues-Rigau LJ. The infertile couple. J Androl 1983; 4: 111-8.

[12] Rhemrev JP, Lens JW, McDonnell J, Schoemaker J, Vermeiden JP. The postwash total progressively motile sperm cell count is a reliable predictor of total fertilization failure during in vitro fertilization treatment. Fertil Steril 2001; 76: 884-91.

[13] Kannel WB, Vasan RS, Levy D. Is the relation of systolic blood pressure to risk of cardiovascular disease continuous and graded, or are there critical values? Hypertension 2003; 42: 453-6.

[14] Scheltens T, Verschuren WM, Boshuizen HC, et al. Estimation of cardiovascular risk: a comparison between the Framingham and the SCORE model in people under 60 years of age. Eur J Cardiovasc Prev Rehabil 2008; 15(5): 562-6.

[15] Stein PK, Barzilay JI, Chaves PH, et al. Novel measures of heart rate variability predict cardiovascular mortality in older adults independent of traditional cardiovascular risk factors: the Cardiovascular Health Study (CHS). J Cardiovasc Electrophysiol 2008; 19(11): 1169-74.

[16] Knuiman MW, James AL, Divitini ML, Ryan G, Bartholomew HC, Musk AW. Lung function, respiratory symptoms, and mortality: results from the Busselton health study. Ann Epidemiol 1999; 9: 297-306.

[17] Folsom AR, Wu KK, Rosamond WD, Sharrett AR, Chambless LE. Prospective study of hemostatic factors and incidence of coronary heart disease. The Atherosclerosis Risk in Communities (ARIC) study. Circulation 1997; 96: 1102-8.

[18] Tsuji H, Venditti FJ, Manders ES. et al. Reduced heart rate variability and mortality risk in an elderly cohort: The Framingham heart study. Circulation 1994; 90: 878-83. 
[19] Delange F. Iodine deficiency as a cause of brain damage. Postgraduate Med 2001; 77: 217-20.

[20] Santiago-Fernandez P, Torres-Barahona R, Muela-Martinez JA, et $a l$. Intelligence quotient and iodine intake: A cross-sectional study in children. J Clin Endocrinol Metab 2004; 89: 3851-7.

[21] Pop VJ, Brouwers EP, Vader HL, Vulsma T, van Baar AL, de Vijlder JJ. Maternal hypothyroxinaemia during early pregnancy and subsequent child development: a 3-year follow-up study. Clin Endocrinol (Oxf) 2003; 59: 282-8.

[22] Haddow JE, Palomaki GE, Allan WC, et al. Maternal thyroid deficiency during pregnancy and subsequent neuropsychological development of the child. N Engl J Med 1999; 341: 549-55.

[23] Pineda-Lucatero A, Avila-Jiménez L, Ramos-Hernández RI, Magos C, Martínez H. Iodine deficiency and its association with intelligence quotient in schoolchildren from Colima, Mexico. Public Health Nutr 2008; 11: 690-8.

[24] Stayner L, Steenland K, Dosemeci M, Hertz-Picciotto I. 2003. Attenuation of exposure-response curves in occupational cohort studies at high exposure levels. Scand J Work Environ Health 2003; 29(4): 317-24.

[25] Richardson D, Wing S, Steenland K, McKelvey W. Time-related aspects of the healthy worker survivor effect. Ann Epidemiol 2004; 14: 633-9.

[26] Brown SC, Schonbeck MF, McClure D, et al. Lung cancer and internal lung doses among plutonium workers at the Rocky Flats Plant: a case-control study. Am J Epidemiol 2004; 160: 163-72.

[27] Choi BC. A technique to re-assess epidemiologic evidence in light of the healthy worker effect: the case of firefighting and heart disease. J Occup Environ Med 2000; 42: 1021-34.

[28] Kulathinal SB, Kuulasmaa K, Gasbarra D. Estimation of an errorsin-variables regression model when the variances of the measurement errors vary between the observations. Stat Med 2002; 21: $1089-101$.

[29] Siebert U, Rothenbacher D, Daniel U, Brenner H. Demonstration of the healthy worker survivor effect in a cohort of workers in the construction industry. Occup Environ Med 2001; 58(12): 774-9.

[30] Steenland K, Stayner L.The importance of employment status in occupational cohort mortality studies. Epidemiology 1991; 2: 41823 .
[31] Steenland K, Deddens J, Salvan A, Stayner L. Negative bias in exposure-response trends in occupational studies: Modeling the healthy workers survivor effect. Am J Epidemiol 1996; 143: 20210 .

[32] Kolstad HA, Olsen J. Why do short term workers have high mortality? Am J Epidemiol 1999; 149: 347-52.

[33] Truett J, Cornfield J, Kannel W. A multivariate analysis of the risk of coronary heart disease in Framingham. J Chronic Dis 1967; 20: 511-24.

[34] Bell ML, Ebisu K, Belanger K. Ambient air pollution and low birth weight in Connecticut and Massachusetts. .Eniviron Health Perspect 2007; 115: 1118-24.

[35] Forsen T, Eriksson J, Tuomilehto J, Runanen A, Osmond C, Barker D. The fetal and childhood growth of persons who develop type 2 diabetes. Ann Intern Med 2000; 133: 176-82.

[36] Hill DJ, Duvillié B. Pancreatic development and adult diabetes. Pediatr Res 2000; 48: 269-74.

[37] Adair LS, Kuzawa CW, Borja J. Maternal energy stores and diet composition during pregnancy program adolescent blood pressure. Circulation 2001; 104: 1034-9.

[38] Ballew M, Hattis D. Reproductive effects of glycol ethers in females--A quantitative analysis. Cambridge, MA: Massachusetts Institute of Technology, Center for Technology, Policy, and Industrial Development 1989.

[39] Smith MK, Randall JL, Read EJ, Stober JA. Teratogenic activity of trichloroacetic acid in the rat. Teratology 1989; 40: 445-51.

[40] Smith MK, Randall JL, Read EJ, Stober JA. Developmental toxicity of dichloroacetate in the rat. Teratology 1992; 46: 217-23.

[41] Randall JL, Christ SA, Hortonperez P, Nolen GA, Read EJ, Smith MK. Developmental effects of 2-Bromoacetic acid in the Long Evans rat. Teratology 1991; 43: 454.

[42] Smith MK, Randall JL, Tocco DR, York RG, Stober JA, Read EJ. Teratogenic effects of trichloroacetonitrile in the Long-Evans rat. Teratology 1988; 38(2): 113-120.

[43] Smith MK, Randall JL, Stober JA, Read EJ. Developmental toxicity of dichloroacetonitrile: A by-product of drinking water disinfection. Fundam Appl Toxicol 1989; 12: 765-72. 